Huntington's chorea are not voluntary or intentional. However, I think that most people would also recognise that much of psychiatric practice is concerned with behaviour that is. Any procedures concerned with managing or influencing voluntary behaviour are surely legitimate subjects of vigorous debate.

JOANNA MONCRIEFF, Research Fellow and Honorary Senior Registrar, Section of Epidemiology and General Practice, Institute of Psychiatry, London SE5 8AF

\section{Continuing Professional Development}

Sir: Gethin Morgan (Psychiatric Bulletin. May 1998, 22, 330-331) provides an interesting insight into his role as Director of the Continuing Professional Development programme. Implicit in his article is a reluctance on the part of psychiatrists to engage in the process of CPD, and he explores issues of cost, time and perceived relevance as aetiological in this motivational disorder. He also touches on the issue of making CPD mandatory.

Psychiatry has always attracted iconoclasts to its profession, and it is perhaps a sign of psychological health that a curmudgeonly group of individualists resist the attempt of their professional organisation to control them. At a time when senior psychiatrists are taking early retirement in droves, and recruitment to the profession is falling, it would seem counterintuitive to raise the standards required in order to practise. If this remains the College's aim. there are few carrots or sticks at its disposal. Inclusion on a White List of participants would seem an inadequate carrot. Exclusion from roles carrying little financial incentive, such as clinical tutor, would seem a brittle stick.

The most potent motivator would surely be to link CPD to the merit award system, and make the holding of such awards contingent upon an adequate engagement in the process of CPD. This would also bring the focus of the merit award system away from academic or managerial success, and back to clinical excellence, where it surely belongs.

JOHN FARNILl MORGAN, Department of Mental Health Sciences, St George's Hospital Medical School, Cranmer Terrace, London SWI7 ORE

Sir: Professor Morgan wishes to spend his second year as Director of CPD, developing and evaluating the College's CPD scheme, and I think that if he did, there would be less need to persuade clinicians to join. I also think it should be possible to offer advice without being part of the scheme at the moment (my own position).
Let us distinguish between CPD, and the College scheme. All clinicians recognise the importance of the former, and would welcome anything which facilitated their own CPD. Most recognise the need to monitor their professional activities in an open and defensible way. However, most do not wish to pay a fee for a service which the College should provide as a core function (as do most others), nor to pay for something which (currently) delivers no perceived benefit. (The spectre of cost effectiveness is inescapable).

The College scheme should be easy to use. free at the point of delivery, actively evaluate and credit local as well as national events and activities, and be of relevance to all sub-specialities.

Were this the case, Professor Morgan would be inundated with applications to join the scheme. and until it is, he faces an uphill task.

ANTHONY E. LIVEseY, Consultant Child Psychiatrist, Child, Adolescent and Family Therapy Service, Edmund Street Clinic, Newbold Moor, Chesterfield, Derbyshire S41 8TD

\section{Administration of electroconvulsive therapy by general practice vocational trainees}

Sir: The College officially frowns on general practitioner (GP) vocational trainee scheme trainees administering electroconvulsive therapy (ECT). This view is expressly stated in their training video and reiterated by Duffett \& Lelliott (1998). In their recent audit, hospitals which include GP trainees in their ECT rotas were 'marked down'. It is far from clear, however, whether this attitude is justified.

It is expected that during their hospital posts. GP trainees participate in the activity of each speciality. They are fully involved in its day-today clinical work and the relevance or otherwise to general practice is usually a secondary consideration. ECT is not a technically demanding procedure which requires years to master; training and experience in its administration can be gained during a six-month placement. Moreover, such experience can be of great benefit to depressed patients seen later in primary care. A GP who has had 'hands-on' experience of any procedure is in a good position to answer questions or allay fears.

The continuing stigma surrounding ECT can be addressed by ensuring that GPs are conversant with its use. Otherwise how can we expect the general public to change its views? 